\section{THE RECONSTRUC'TIVE SURGERY OF THE HIP.*}

Abstract of the Bradshaw Lecture.

$$
\text { BY }
$$

ERNEST W. HEY GROVES, M.S., F.R.C.S., PROFESSOR OF SURGERY, UNIVERSITY OF BRISTOL.

The hip-joint, the largest and most important in the body, presents special difficulties and special displacements. It is more liable to serious disease and congenital dislocation than any other joint. Possibly this may be due in part to the evolutionary change from the quadruped to the biped gait and progression.

\section{Fracture of the Neck of the Femur.}

Fractures of the true neck of the femur-that is, of the bone proximal to the intertrochanteric line-present very special features. Unless impacted these fractures never undergo natural union, and yet if artificial impaction is brought about, hony union will occur just as certainly as in any fracture elsewhere. Non-union, which is tho natural event in these cases, is due to four causes-namely, want of apposition, poor blood supply, interposed capsule, and the action of the synovial fluid. Of these, the first two are by far the most important. If efficient treatment is delayed for mcre than a few weeks marked atrophy occurs in the proximal fragment, and after such an event perfect restitution either of form or function is impossible. The three essential points in the treatment are: early intervention, accurate apposition, and firm fixation. If these points are observed, firm bony union can be secured in practically all cases, whether in old or young.

The mcthod advocated by Whitman is a great advance on previous mcdes of treatment. Under an anaesthetic the leg is pulled downwards, inverted and abducted, thus impacting the fracture. The abducted limb is fixed in a plaster spica for three to six months. The objections to this mothod consist in its uncertainty, and the very great torture and tedium of keeping an adult in a plaster case for several months. The uncertain result is due to the facts that manipulation of the leg cannot correct a misplaced proximal fragment, or get rid of that portion of the capsule which may lie between the broken surfaces.

Fixing the fracture by means of a bone peg gives a much more certain and perfect union with less strain upon the patience and fortitude of the patient. The joint is exposed by an anterior incision, the capsule opened, the fractured surfaces laid bare, the fracture accuratcly replaced by manipulaticn, and a square peg $4 \frac{1}{2}$ in. long by $3 / 8$ in. thick driven from the base of the great trochanter through the neck into the head. The limb is put up in moderate flexion and abduction, steadied by slight traction. In six weeks' time the patient can walk with a calliper, and in three to six months can resume a normal life.

Special modifications of the pegging operation are useful in certain circumstances.

The peg may be inserted from above. This is useful when the proxinal fragment is very small and the line of fracture difficult to expose outside the hip socket. The head of the bone is dislocated and nailed on to the neck, after which the bone is replaced in position.

In old cases, where the fracture is of long standing, it may be useful to employ a living bone peg, taken preferably from the fibula, because this type of peg will substitute some new bone in place of that lost by atrophy.

The peg may be inserted blindly-that is, without exposing the joint at all. This method should be reserved for patients whose age or debility makes it desirable to avoid the more serious operation. The drill hole into the neck and the insertion of the peg should be made under the guidance of the $x$ rays. Conditions of slipped epiphysis should also be treated by the pegging operation; which is capable of restoring the bone to its perfect original form.

* Delivered before the Royal College of Surgeons of England, November 11th, 1926. The full text of the lecture will be published in the January
Ankylosis of the Hip.

There is no entirely satisfactory method of treating an ankylosed hip. It is comparatively easy to cure the patient of pain and to correct deformity, but it is extraordinarily difficult to secure mobility and stability at the same time, therefore only those cases are operated upon in which double ankylosis of the hips or simultaneous ankylosis of the hip and knee makes some treatment imperative. The more complicated methods of arthroplasty tend to Jeave the patient with a very stiff hip. It seems better, therefore, to be content with some modification of excision of the head of the femur. Two suggestions are made in order to secure both mobility and stability after this cxcision. To attain mobility, the capsular ligament is used as an envelope for the cut neck of the femur. To prevent the bone becoming dislocated the cxcised head of the femur is cut into two fragments and affixed to the upper margin of the acetabulum.

\section{Congenital Dislocation of the Hip.}

It is now generally recognized that early cases of congenital dislocation of the hip can be efficiently treated and cured by manipulation. But it is not realized that in older children when manipulative reduction is impossible a great deal can still be done by open operation to get firm and useful hip-joints. It is worse than useless to employ elaborate and difficult methods of manipulative reduction in these older cases. The main obstacle to reduction is the tight constriction of the capsule. No force or cunning can compel the head of the femur measuring one inch in diameter to pass through a thick constricted capsule presenting a channel of about a quarter of an inch.

Open exposure of the joint through an anterior incision makes it quite easy to reduce the dislocation after the constricted capsule has been slit open. The problem then arises as to the best methods of retaining the femur in its socket. In one method the acetabulum is deepened intil it affords a socket sufficient to take the whole femoral head. This gives a very secure joint, but one which is liable to become stiff. In another method, that which has been most frequently used, the cartilage of the acetabulum is left undisturbed and a new rim is added to the socket by turning. down a part of the outer surface of the iliac bone. In a third method the capsule is cut from its attachment to the pelvis and tied round the head of the femur, the acetabulum is gouged out, the liead of the bone wrapped in the capsule is placed in the socket and anchored there by stitches which fix the capsule to the floor of the acetabulum.

In the late or adult cases of congenital dislocation a great deal can be done to cure both the pain and the lameness by a subtrochanteric osteotomy, putting up the leg in full abduction. But this is only suitable for unilateral cases. When the dislocation is bilateral, the head of one femur can be brought down into the socket by removing about two inches of the shaft of the bone below the small trochanter. This will give a firm hip on one side and the two legs will be of the same length. At a later date, if necessary, an osteotomy may be done on the opposite side.

Infantile Paralysis affecting the Hip Muscles.

Extensive infantile paralysis of the lower limb can to a large extent be made good by means of apparatus which fixes and controls the knee and ankle joints, but paralysis of the gluteal muscles leads to a complete inability to balance the trunk upon tho leg and necessitates the permanent use of crutches. It has been suggested that the lost abductors may be replaced by using the tensor fasciae femoris or the erector spinae muscles. Neither of these muscles singly can make a very efficient abductor, partly because one lies in front and the other behind the required line of action, and, in the case of the back muscle, because of the difficulty in getting a necessary tendinous insertion. By combining these two muscles an efficient digastrio abductor of the hip is formed. A long incision is made on the outer side of the thigh; the ilio-tibial band is isolated and cut above the knee; the fascial band forming the tendon of the tensor muscle is brought backwards through the base of the great trochanter; the erector spinae muscle is exposed by a vertical incision, and the lower portion 
isolated by cutting through its lower origin and splitting this part of the muscle upwards for about four inches; the ilio-tibial band is brought backwards and upwards through a tunnel under the skin and fixed to the isolated part of the erector spinae muscle.

\section{9ritish Attedical Aszoniation.}

\section{PROCEEDINGS OF SECTIONS AT THE ANNUAL MEETING, NOTTINGHAM, 1926.}

\section{SECTION OF NEUROLOGY AND PSYCHOLOGY.}

- E. Farquhar Buzzard, M.D., F.R.C.P., President.

\section{DISCUSSION ON MANIC-DEPRESSIVE PSYCHOSIS.}

\section{OPENING PAPER}

\section{BY}

EDWARD MAPOTHER, M.D., M.R.C.P., Medical Superintendent, Maudsley Hospical, London.

THE task of introducing for discussion the subject of the manic-depressive psychosis has an engaging but spurious air of simplicity. The disorder arouses a natural sympathy and interest in normal people. The anomalies of the patient have none of that apparently meaningless and inexplicable quality which makes the schizophrenic so remote and renders so improbable the truth that he once thought and acted like ourselves. On the contrary, if the term " manic-depressive psychosis" is used in any but the narrowest sense it is obvious that in many cases we are dealing with a merely quantitative deviation, that the disturbance consists in a response similar in kind to that which like circumstances might provoke in us, but morbidly prolonged or disproportionate or disastrous in degree. Even if we were to confine the term to those cases showing apparently spontaneous mutations of mood and activity there are few of us without personal experience of analogous phases.

In handling the practical problems of causation, diagnosis, prognosis, and treatment it is impossible to be both comprehensive and detailed. I shall aim at raising points for discussion, but if at times 1 express myself dogmatically I hope this will be recognized as merely provocative.

\section{Delimitation of Manic-Depressive Psychosis: Relation} to Neuroses.

The primary problem is what meaning should be attached to the term "manic-depressive psychosis." There is no constant and specific cause, and no distinctive bodily change recognizable during life or after death. The range of the term is a matter of convention; at present there is no agreement, and no one with the authority to impose one. Yet all discussion, at least as to the problems of causation, diagnosis, and prognosis, must depend on delimitation. All would probably agree that under the heading of " manic-depressive psychosis" are included cases of functional mental disorder which show as their predominant features one of a contrasting pair of anomalous types of reaction.

I. The depressive reaction comprises (a) Morbid dissatisfaction (with the self or circumstances) in one of its varieties; colouring of thought and action thereby ; persistence or hyperexcitability of various alternative reactions (psychomotor and visceral) expressive of the mood. (b) A sense of difficulty in thought, action, and feeling of all other kinds and a varying true incapacity for activity in relation to external reality.

II. The manic reaction comprises: (a) Morbid satisfaction (with the self or circumstances); colouring of thought and action thereby and objective expressions of this mood. (b) Fallacious sense of power and misdirected hyperactivity.

The question, however, which immediately arises is whether all or only some such cases should be included; whether it is necessary to limit the application of the term by reference to varieties of these symptoms, their intensity, time relations, and causes, or by such criteria as insight and amenability to treatment. It will be generally agreed that subdivision in virtue of details of the known (for example, of past course and present symptoms) serves little purpose unless the types discriminated are correlated with differences in the unknown-for example, in causation, prognosis, or treatment. The term originated in the attempt of Kraepelin to establish a correlation between certain syndromes and course, between transverse and longitudinal section in the severer psychoses. Hence Kraepelin's invention of the category manic-depressive psychosis as one of the standard types to which cases of grave mental disease more or less conform.

It was emphasized that cases of the manic-depressive type did not in most instances tend to dementia between attacks or even after a number of such. It is doubtful whether this is more than a truism which could be briefly expressed in nore modern terms by saring that in a given patient there is no strong reason to anticipate marked and terminal schizophrenia in the absence of minor and early changes of the same kind. Nevertheless cases presenting the manicdepressive syndrome in absolutely pure form during their early stage do sometimes end as trpical dementia praecox.

In earlier years spontaneous occurrence-that is, lack of traceable relation to any external causes-was one of the features ascribed to typical manic-depressive psychosis, but in fact the degree to which internal and external factors co-operate is infinitely variable.

It is unproven and improbable that any mental syndrome is due to a specific cause, and consequently there is no more likelihood of a constant course in mania or depression than in jaundice.

Kraepelin himself in later years has fully recognized that in addition to the striking cases of almost purely affective disturbance reaching the intensity to which we commonly give the name of a psychosis and showing a clear-cut phasio course there are many others. We see cases in which chronic anomalies, like in kind to those of the attack though varying infinitely in degree, are present before or after. These cases merge into those where constitutional symptoms of one kind or the other are pretty constantly present and undergo mere fluctuations. Thus there is a complete gradation to certain minor disturbances which, whether continuous or phasic, are usually termed neuroses,

Kraepelin, if anyone, has the right to settle what conditions the term " manic-depressive psychosis" shall connote. $\mathrm{He}$ has come to the conclusion that it is simplest to include all cases showing the affective excesses and also the " syntonic" types of intellectual and conative disorder to which I have referred, and this regardless of their intensity and time relations. He has not been followed by all who have borrowed their names and ideas from his earlier work, but personally I entirely agree with his later views in this matter.

The distinction between what are termed neuroses and psychoses has really grown out of practical differencès, particularly as regards certification and asylum treatment. It has become customary to call those types and degrees of montal disorder which rarely call for such measures by the name of neuroses. I can find no other basis for the distinction; neither insight, nor co-operation in treatment, nor susceptibility to psychotherapy will serve.

I am aware that this view will probably be challenged. There is a small group who insist on importing animism into psychopathology. Most of these authors seem to propound the paradox that mental disorders are disturbances in the nervous functions and structures, while what we term neuroses are disturbances of an entity called mind without persistent physical basis, though others, including McDougall, would, I believe, include manic-depressive psychosis in the latter category. In spite of the profoundest respect for those who hold these theories, and in spite of the traditional upbringing during childhood, I confess that these views now convey no meaning to me. We admit the mystery of consciousness, but to assume that an enduring physical basis for habitually abnormal behaviour is probably non-existent because at present its exact nature is not 